\title{
EFFECT OF FOLIAR COPPER-CONTAINING SUPERABSORBENT POLYMERS ON NUTRITIONAL CHARACTERISTICS AND MYCOTOXIN CONTAMINATION OF WHEAT KERNEL
}

\author{
Ivana Kolackova ${ }^{1}, H_{a n a}$ Abigail Gruberova ${ }^{1}$, Ondrej Kratochvil ${ }^{1}$, \\ Daria Baholet ${ }^{1}$, Jiri Skladanka ${ }^{1}$, Josef Jancar ${ }^{2}$, Petr Skarpa ${ }^{3}$
}

\footnotetext{
${ }^{1}$ Department of Animal Nutrition and Forage Production, Faculty of AgriSciences, Mendel University in Brno, Zemědělská 1, 61300 Brno, Czech Republic

${ }^{2}$ Central European Institute of Technology, Brno University of Technology, Purkyňova 123, Brno 612 00, Czech Republic

${ }^{3}$ Department of Agrochemistry, Soil Science, Microbiology and Plant Nutrition, Faculty of AgriSciences, Mendel University in Brno, Zemědělská 1, 61300 Brno, Czech Republic
}

Link to this article: https://doi.org/10.11118/actaun.2021.007

Received: 7. 12. 2020, Accepted: 22. 12. 2020

To cite this article: KOLACKOVA IVANA, GRUBEROVA HANA ABIGAIL, KRATOCHVIL ONDREJ, BAHOLET DARIA, SKLADANKA JIRI, JANCAR JOSEF, SKARPA PETR. 2021. Effect of Foliar Copper-Containing Superabsorbent Polymers on Nutritional Characteristics and Mycotoxin Contamination of Wheat Kernel. Acta Universitatis Agriculturae et Silviculturae Mendelianae Brunensis, 69(1): 71-78.

\begin{abstract}
Novel use of superabsorbent polymers to deliver copper-based foliar fertilization was tested as a means against fungal mycotoxin production and monitor its effect on nutritional characteristics of wheat. Experiment was located in Žabčice, South Moravia region of the Czech Republic, tested wheat variety was 'Julie'. Differences in fertilization medium (water or superabsorbent polymers) and copper treatments (control, $\mathrm{CuO}, \mathrm{CuSO}_{4}, \mathrm{Cu}-\mathrm{EDTA}$, CuO-nano) were tested. Effect of different variants on percentage of ash, crude protein, crude fat and crude fiber, acid detergent fiber, ashfree neutral detergent fiber, lignin, cellulose and starch were determined. Moreover, concentration of deoxynivalenol and T-2 toxin depending on the variant was measured. The highest amounts of crude fat and crude fiber were observed in variant of Cu-nano with superabsorbent polymers, the lowest in $\mathrm{CuO}$ respectively. Higher amount of cellulose was found in SAP control, lowest in water control. There were no significant differences in other nutritional parameters. Of the evaluated mycotoxins, we did not detect the deoxynivalenol in any of our samples. For the second evaluated mycotoxin, there was also no difference observed in T-2 toxin production.
\end{abstract}

Keywords: feed quality, superabsorbent polymers, nanoparticles, fertilizer, trichothecenes

\section{INTRODUCTION}

Agricultural soil is contaminated in many parts of the world by heavy metals such as $\mathrm{Zn}$, Cu and Cd (Yadav, 2010). This could be due to the longterm use of phosphatic fertilizers, sewage sludge application, industrial waste and bad watering practices in agricultural land (Schwartz et al., 2001).
Superabsorbent polymers (SAP) can absorb and store up to 1000-times more water than their mass, and by holding a large amount of polyfunctional groups (amino and imino groups) they can effectively adsorb heavy metal ions (Mikula et al., 2020; Huang et al., 2011). The application of SAP positively influences crop production improved soil physical properties and can be used to reduce heavy 
metal hazard in plant in contaminated soils (Prasad and Freitas, 1999). SAP have the ability to decrease water stress by reducing evaporation losses in plants in both foliar and soil application, therefore they can be used as a medium for micronutrient foliar sprays (Moradi-Ghahderijani et al., 2017; Mikula et al., 2020).

Use of nanoformulations can maximize crop production while minimizing the use of pesticides. The high surface of nanoparticles provides an improved matrix for the immobilization of desired biomolecules for signal amplification in biosensors for the detection of mycotoxins (Thipe et al., 2018).

Copper is an important micronutrient that is also widely used as an antimicrobial agent in plant protection against bacteria and fungi, mainly in organic and integrated agriculture (Kristl et al., 2019). Foliar application of copper increases the levels of vitamins $\mathrm{A}$ and $\mathrm{E}$, and their precursors in plants (Kristl et al., 2019). Generally, foliar application of $\mathrm{Cu}$ fertilizers is considered more effective than soil application for immediate response in grain yield of wheat by increasing the production of structural molecules and decrease of fungal pathogen occurrence (Datnoff et al., 2007).

Copper nanoparticles have been proposed as a new alternative to traditional copper-based fungicides. Their potential higher efficiency dwells in their small size (1-100 nm), and high surface to volume ratio which allows closer interaction with microbial membranes (Ramyadevi et al., 2012). Nanoparticles are 10-100 fold more toxic to fungal spores than to hyphae, which suggest a potential use as a mycotoxin production control agent (Malandrakis et al., 2019).

Mycotoxins are stable secondary metabolites that can be produced by fungal species under specific conditions and may be a cause of severe health problems in both animals and humans
(Bryden, 2011). It was previously stated that 20$40 \%$ of crops have been said to be lost each year due to pests and diseases, furthermore $25 \%$ of grain crops are contaminated with mycotoxins, mainly with deoxynivalenol (DON) as one of the five most commonly occurring (Worrall et al., 2018; Bryden, 2011; Rodrigues and Naehrer, 2012). Plant disease is a major problem for production, and the decrease in crop yield (Ramezani et al., 2019; Cwalina-Ambroziak et al., 2017). Wheat is one of the most prone crops to mycotoxin contamination in temperate regions, such as DON or T-2 toxins. Both mycotoxins belong to the class of trichothecenes, most commonly produced by often phytopathogenic genus Fusarium (and less commonly by other fungal species) (Cole et al., 2003; McMullen et al., 1997).

The main hypothesis of this study was that SAP can serve as a medium for delivering $\mathrm{Cu}$ particles as well as water, but with potential benefit of combating water stress. Secondly, $\mathrm{Cu}$ can have beneficial effects on nutritional status and antifungal properties that decrease the amounts of trichothecenes in wheat kernel.

\section{MATERIALS AND METHODS}

Experiment on the effects of foliar application of SAP infused with four different forms of copper particles was established in Žabčice field station (49 $\left.00^{\prime} 50.3^{\prime \prime} \mathrm{N}, 1^{\circ} 36^{\prime} 03.6^{\prime \prime} \mathrm{E}\right)$ in South Moravia region of the Czech Republic. This region is characterized by average precipitation distributed unevenly during the year and frequent winds enhancing water evaporation of already arid environment in summer. Environmental conditions during the experimental years and normal conditions at Žabčice experimental station are presented in Fig. 1. Meteorological parameters

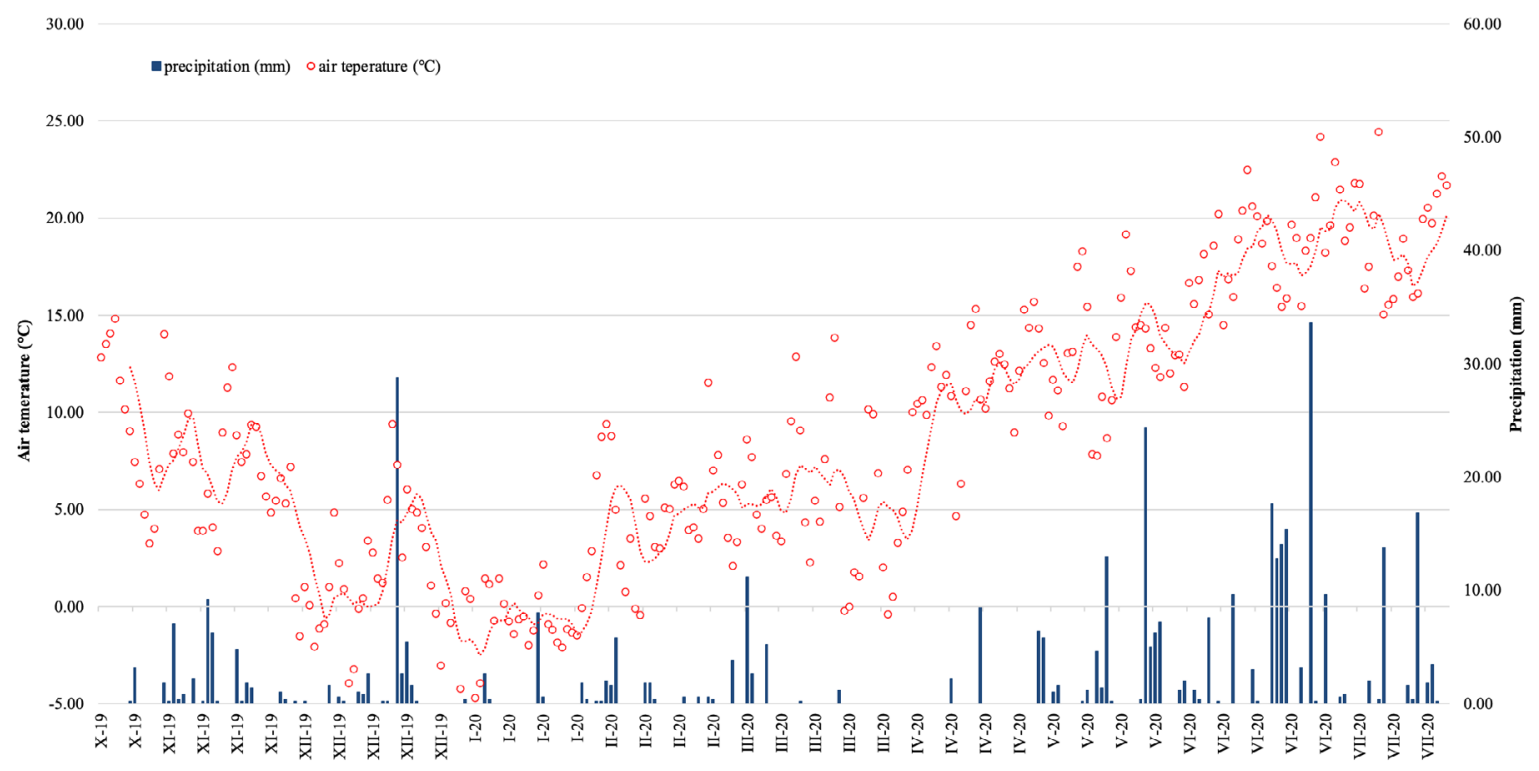

1: Environmental conditions in Žabčice during the experimental period 
were collected in dataloggers (Campbell, USA) of agroclimatologic station situated on the field station. Experimental area has clay and loam fluvisol soil type, with high levels of ground water (up to 0.8-2.5 m deep below the soil surface).

\section{Plant Material and Trial Establishment}

Experiment was established in 2019, fertilization by $90 \mathrm{~kg} / \mathrm{ha} \mathrm{P}_{2} \mathrm{O}_{5}$ and $120 \mathrm{~kg} / \mathrm{ha} \mathrm{K}_{2} \mathrm{O}$ and presowing ploughing was done. Sowing date was 21. 10. 2019, wheat cultivar 'Julie' was used (sowing rate was 4 million germinating seeds per ha). Pesticide treatments comprised ELATUS ERA (1//ha) applied on 12. 5. 2020, PROTEUS 110 OD (0.6l/ha) applied on 29. 5. 2020, PROSARO $250 \mathrm{EC}(0.75 \mathrm{l} / \mathrm{ha})$ applied on 9. 6. 2020. Harvest date was 24. 7. 2020. Each variant was sown in three repetitions and therefore all subsequent analyses of samples were done in three repetitions per variant.

Foliar application of four copper treatments (CuO, $\mathrm{CuSO}_{4}, \mathrm{Cu}-\mathrm{EDTA}$, CuO-nano), each prepared as a water or SAP solution, and two control variants (water without $\mathrm{Cu}$ and SAP solution without $\mathrm{Cu}$ ) was done 16. 4. 2020 at the beginning of stem elongation (BBCH 30) (Zadoks et al., 1974).

For each variant, copper foliar application of one dose (200 g/ha $\mathrm{Cu}$ ) was used. The liquid SAP was used for preparation the SAP solution (rate water:liquid SAP was 50:1 (v:v)). The liquid SAP was a dispersion of modified polysaccharide hydrogel microparticles in an aqueous solution of commercial non-ionic surfactants (Aqueduct), natural hygroscopic compound and natural biostimulant with the overall $\mathrm{pH}$ adjusted to 6.5.

\section{Analyses of Wheat Samples}

Samples were created by separating the harvested kernels from impurities on $1 \mathrm{~mm}$ sieve and subsequently gathering approx. $1 \mathrm{~kg}$ at random for the further analyses. Wheat kernels were homogenized by grinding to a fine powder (particle size $<1 \mathrm{~mm}$ ) after completely cooled. Samples were then stored in an airtight containers away from heat and light until further analysis.

Laboratory Dry Matter was determined from a difference in weight before and after drying of samples (created by a loss of moisture) at $105^{\circ} \mathrm{C}$ for 24 hours using the forced-air oven.

By igniting the sample at $600^{\circ} \mathrm{C}$ was organic matter fully oxidized and resulting inorganic matter was weighted to calculate ash content of the sample.

Crude protein (CP) was determined using Kjeldahl method. Crude fat and crude fiber (CF) content was determined by solid's extraction using Soxhlet method. Acid detergent fiber (ADF), ash-free neutral detergent fiber (aNDF) and acid detergent lignin (ADL) were measured by ANKOM Fiber Analyser (ANKOM Technology, Macedon, USA). Starch was analyzed polarimetrically. ADF, aNDF, ADL and starch were analyzed according to the Commision Regulation (EC) No. 152/2009 on methods of sampling and analysis for the official control of feed.

Mycotoxin presence and quantity were determined by enzyme-linked immunosorbent assay (ELISA). Two mycotoxins in the class of trichothecenes were measured, Deoxynivalenol (DON) and T-2 toxin. ELISA kits were obtained from MyBioSource, Inc. (San Diego, USA). Samples were analysed according to the producers' instructions.

\section{Statistical Evaluation}

All measurements were statistically evaluated and presented in the form of figures using Microsoft Excel (Microsoft Corporation, Redmond, USA) and Statistica, version 12.0 (TIBCO Software, Palo Alto, USA). Results are expressed as mean from three samples per variant or mean \pm standard deviation. Normality of data was tested by Shapiro-Wilk test. Statistical significance of differences among observed factors was determined using one-way ANOVA and Sheffe test for normal data. Differences with $\mathrm{P}<0.05$ were regarded as statistically significant.

I: Details on used treatments including copper fertilizer forms and dissolving mediums

\begin{tabular}{|c|c|c|}
\hline \multicolumn{2}{|r|}{ Variant } & Medium \\
\hline \multicolumn{2}{|r|}{ Water Control } & water \\
\hline $\mathrm{CuO}$ & YaraVita COPTRAC 500 & water \\
\hline $\mathrm{CuSO}_{4}$ & $\mathrm{CuSO}_{4} \cdot 5 \mathrm{H}_{2} \mathrm{O}$ & water \\
\hline Cu-EDTA & Lister $\mathrm{Cu}$ & water \\
\hline \multirow[t]{2}{*}{ CuO-nano } & Cu nanopowder, < 50 nm - Sigma (544868) & water \\
\hline & SAP Control & SAP solution \\
\hline $\mathrm{CuO}$ & YaraVita COPTRAC 500 & SAP solution \\
\hline $\mathrm{CuSO}_{4}$ & $\mathrm{CuSO}_{4} \cdot 5 \mathrm{H}_{2} \mathrm{O}$ & SAP solution \\
\hline Cu-EDTA & Lister $\mathrm{Cu}$ & SAP solution \\
\hline CuO-nano & Cu nanopowder, < 50 nm - Sigma (544868) & SAP solution \\
\hline
\end{tabular}




\section{RESULTS}

Analyses of nutrient content and mycotoxin contamination was performed. Average values of wheat kernel samples depending on used medium (water or SAP solution) and treatment $\left(\mathrm{CuO}, \mathrm{CuSO}_{4}\right.$, Cu-EDTA, CuO-nano) were measured.

Highest ash content (Fig. 2) was observed in $\mathrm{H}_{2} \mathrm{O}$ Control $(1.85 \pm 0.23) \%$ lowest in $\mathrm{H}_{2} \mathrm{O}$ CuO-nano $(1.67 \pm 0.03) \%$. However, there were no significant differences observed among any of the $\mathrm{H}_{2} \mathrm{O}$ or SAP treatment variants.

This was the case in $\mathrm{CP}$ contents as well. Highest $\mathrm{CP}$ content was measured in $\mathrm{H}_{2} \mathrm{O}$ Control $(11.73 \pm 0.28) \%$, lowest in SAP CuO $(10.01 \pm 0.51) \%$, but no significant differences were observed.

There was no significant difference between crude fat contents of $\mathrm{H}_{2} \mathrm{O}$ variants. $\mathrm{H}_{2} \mathrm{O}$ and SAP Control had similar fat contents. There were, however, significant differences among all of the SAP treatments. SAP CuO-nano had highest values of fat contents overall $(2.25 \pm 0.07) \%$, followed by SAP Cu-EDTA $(2.14 \pm 0.15) \%$. Lowest fat content was observed in $\mathrm{CuO}(1.57 \pm 0.12) \%$.

No significant differences among treatments were observed in case of starch.

Similarly to fat, there were no significant differences in $\mathrm{CF}$ between $\mathrm{H}_{2} \mathrm{O}$ and SAP Control variants (Fig. 3). Highest CF content was observed in SAP CuO-nano $(2.52 \pm 0.23) \%$. There was significantly lower CF content in $\mathrm{H}_{2} \mathrm{O} \mathrm{CuO}(1.40 \pm 0.20) \%$ and $\mathrm{H}_{2} \mathrm{O}$ CuO-nano $(1.64 \pm 0.19) \%$.
There were no significant differences in ADF between $\mathrm{H}_{2} \mathrm{O}$ and SAP Control variants. Highest ADF content was observed in SAP Control $(3.84 \pm 0.12) \%$, lowest in $\mathrm{CuSO}_{4}(3.08 \pm 0.28) \%$. When compared to $\mathrm{H}_{2} \mathrm{O}$ CuO-nano $(3.79 \pm 0.05) \%$, ADF contents were significantly lower in SAP CuO-nano $(3.11 \pm 0.24) \%$. No significant differences were observed in aNDF or ADL.

Cellulose contents were very similar in $\mathrm{H}_{2} \mathrm{O}$ treatments, with no differences. When compared to $\mathrm{H}_{2} \mathrm{O}$ Control variant, SAP Control did not have significantly higher $(\mathrm{p}<0.05)$ cellulose content, however significance was close to the given threshold $(p<0.06)$. Highest cellulose content was observed in SAP Control $(3.24 \pm 0.18) \%$, followed by CuO-nano $(2.59 \pm 0.30) \%$ and $\mathrm{CuO}(2.53 \pm 0.20) \%$. Lowest content was observed in $\mathrm{CuSO}_{4}(2.48 \pm 0.19) \%$.

DON was below the limit of quantification in every sample. Average T-2 toxin concentration in our samples was $24.34 \pm 8.25 \mathrm{ng} / \mathrm{ml}$ (Fig. 4). There were no significant differences among treatments in case of $\mathrm{T}-2$ toxin.

\section{DISCUSSION}

In our study we compared the effects of foliar $\mathrm{Cu}$ fertilization in four different forms and use of two mediums on nutrient content in wheat. Foliar fertilization supplies the plant by nutrients absorbed through stomatal apertures and cuticle, which is permeable to water and ions as well as to polar compounds (Schreiber and Schönherr, 2009; Fernandez and Eichert, 2009). Medium used for

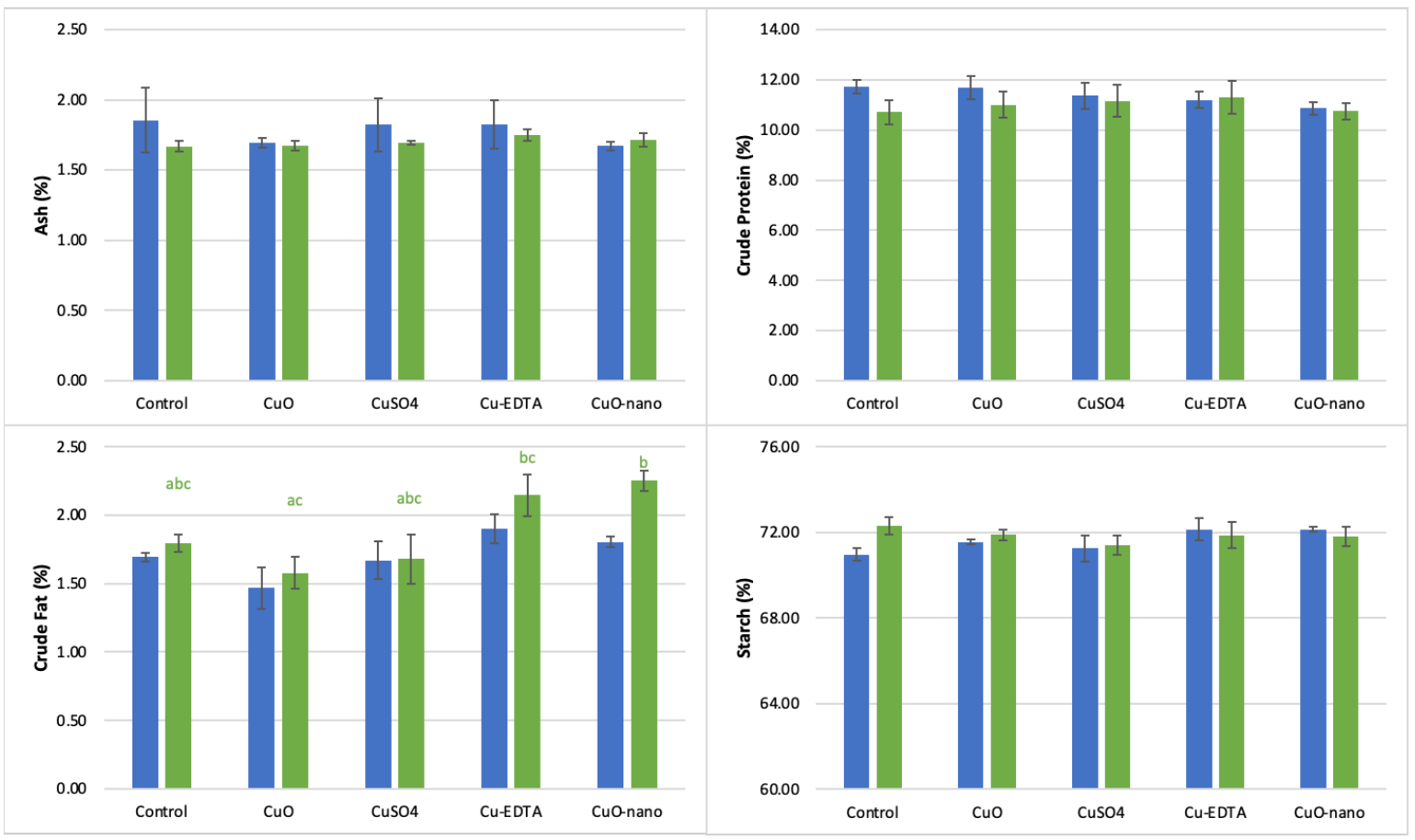

2: Differences in ash, crude protein, crude fat and starch content depending on the treatment variant Legend: Blue columns mark the use of water as a mixing medium, green columns mark the use of SAP solution. Results are expressed as a mean; whiskers mark the standard deviation (SD). 


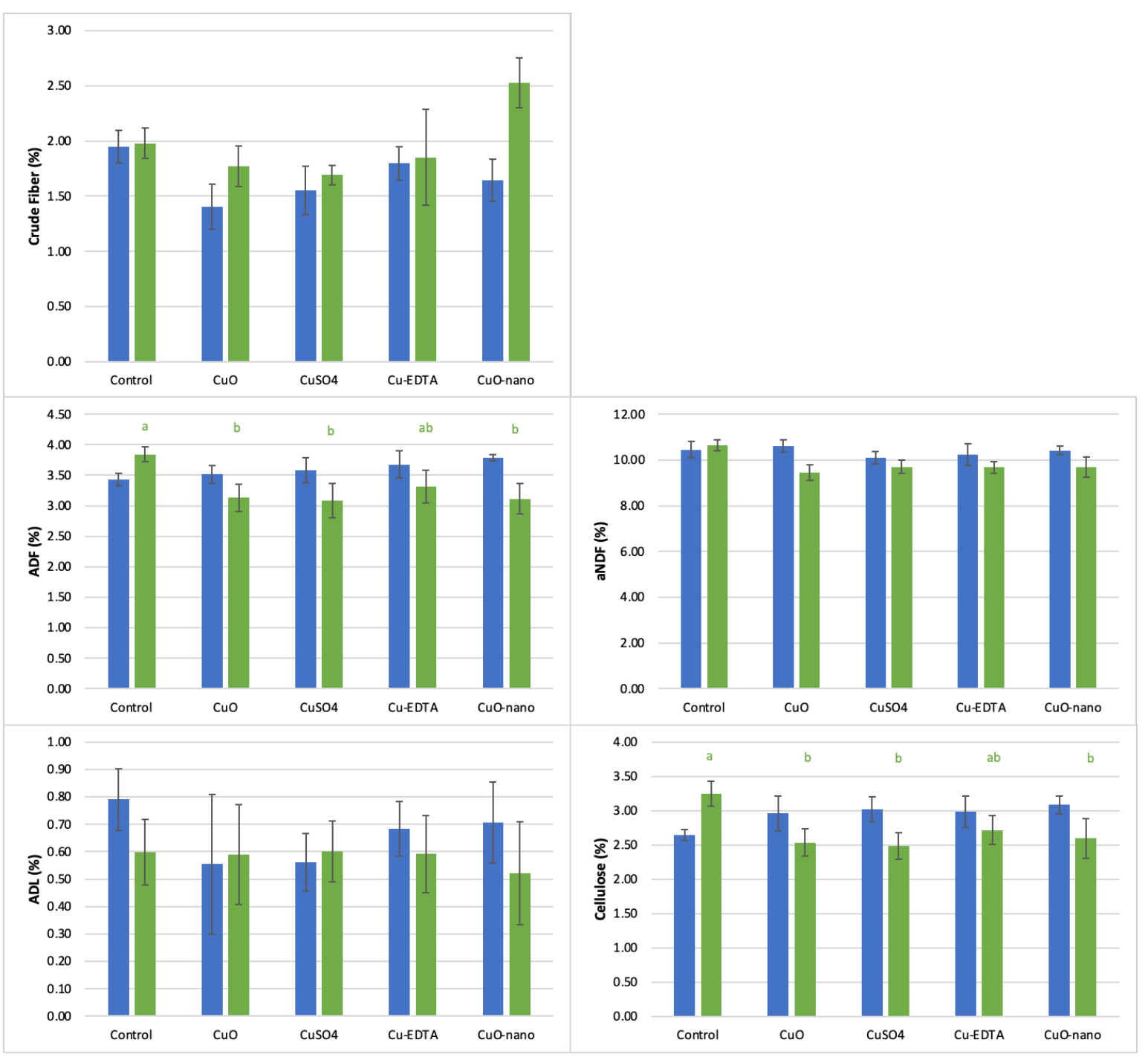

3: Differences in crude fiber, $A D F$, aNDF, $A D L$ and cellulose content depending on the treatment variant Legend: Blue columns mark the use of water as a mixing medium, green columns mark the use of SAP solution. Results are expressed as a mean; whiskers mark the standard deviation (SD).

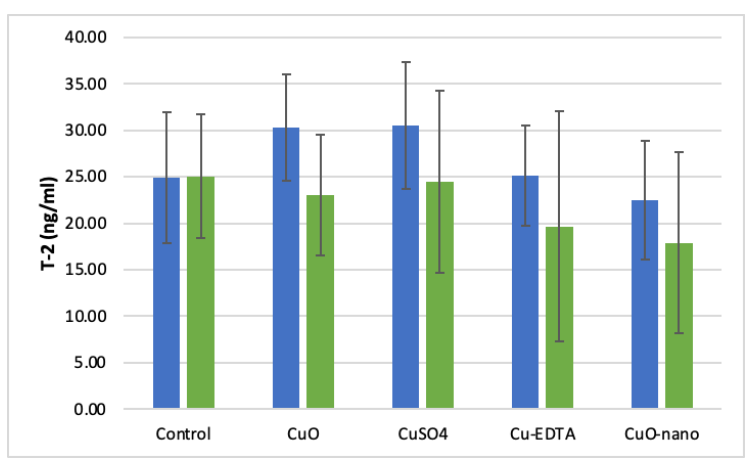

4: Differences in T-2 toxin content depending on the treatment variant

Legend: Blue columns mark the use of water as a mixing medium, green columns mark the use of SAP. Results are expressed as a mean; whiskers mark the standard deviation (SD). fertilizer application needs to have the ability to be sufficiently transferred into the plants above-ground biomass, however, early evaporation of the medium may obstruct that. When using the $\mathrm{Cu}$ foliar fertilizers, rain and irrigation-mediated depletion of nutrients may cause soil contamination (Tiller and Merry, 1981). Studies have shown that nanoformulations of $\mathrm{Cu}$ volatilization and leaching are stored in soils and sediments, which, together with volatilization and leaching of other nutrients can pose a threat to aquatic organisms after events causing soil erosion and eventual run-off (Keller et al., 2017; Azeem et al., 2014). Superabsorbent polymers (SAP) are able to imbibe water and slowly release nutrients (Azeem et al., 2014). In our experiment SAP performed very similarly to water in case of control variants which proves its suitability as a foliar fertilization medium. However, even though some statistical differences were found between nutrition 
content in treatments using water as a medium (CF), differences in $\mathrm{Cu}$ forms were more profound in SAP variants (fat, $\mathrm{CF}$ and ADF). This suggests that SAP did enhance plant absorption ability of the different $\mathrm{Cu}$ forms more than water and that $\mathrm{Cu}$ nano SAP is the most suitable for increasing the fat, $\mathrm{CF}$ and cellulose content in wheat kernel.

Cu-deficiency results in absent formation of lignin and secondary cell wall, and moreover, may negatively affect starch content (Datnoff et al., 2007). Based on our results, $\mathrm{Cu}$ fertilization does not affect starch or lignin content in comparison to control. It may, however, increase cellulose content in wheat kernel. Lower CF contents were found in water variants than in SAP. Higher fiber content can be caused by longer availability and therefore higher absorption of $\mathrm{Cu}$ from foliar fertilization by wheat mediated by SAP.

Experiment of Malandrakis et al. (2019) showed, that mycelial growth was suppressed by $\mathrm{Cu}$ nanoparticles and their antifungal effect was overall higher that $\mathrm{Cu}(\mathrm{OH})_{2}$-based fungicide, $\mathrm{CuSO}_{4}$, or silver and zinc nanoparticles. However, effects were dependent on fungal species. Our experiment indirectly confirms this effect. In our study, higher effect on lowering T-2 concentration was indicated by $\mathrm{Cu}-$ nano than $\mathrm{CuSO}_{4}$, which may indicate fungal suppression of T-2 producers.

Overapplication or use of high amounts of fungicides have been proven to affect feed intake by animals and cause increase in heavy metal (mostly $\mathrm{Cu}$ ) pollution in soil (Loland and Singh, 2014). In the study of Haerr et al. (2015) was dry matter intake lower for dairy cows fed with corn silage treated with fungicide, and this effect has linear correlation with amounts of fungicide used. Nanoformulations of fungicides based on copper, similar to tested variants in our study, can be used in smaller amounts and therefore potentially prevent this issue from occurring (Kristl et al., 2019).

This study also observed the effects of used treatments on DON and T-2 content in wheat kernel. $\mathrm{Cu}$ fertilization has beneficial effects for plant defense directly by acute toxicity to fungi as well as indirectly by boosting the general disease resistance. This comprises production of antimicrobial compounds, regulation of enzyme systems and regulation of disease resistance genes in plants (Datnoff et al., 2007). This, however, is not in accordance with our mycotoxin results. There was no significant difference between control and other variants, therefore foliar application probably would not have affected disease resistance against trichothecenes-producing fungal species. On the other hand, study of Datnoff et al. (2007) concludes that late flowering and maturation caused by $\mathrm{Cu}$ deficiency may be the cause of higher Fusarium incidence on wheat, depending on the weather conditions. This fact suggests higher influence of $\mathrm{Cu}$ fertilization if the plant is Cu-deficient and fungal pressure is particularly high in that season. In our experiment, no Cu-deficiency symptoms were not detected, so it is safe to assume that this may be the reason of low influence of $\mathrm{Cu}$ fertilizer on mycotoxin production.

Conditions for DON and T-2 toxin production are specific for each mycotoxin, even though they can be both produced by Fusarium spp. (Skládanka et al., 2014). Fusarium spp. infection is abundant when high humidity at the time of flowering occurs in temperate areas. It can contaminate grains such as wheat, barley, oat, rye and maize ("Deoxynivalenol in food and feed," 2013). DON is often characterized as a signal mycotoxin ("BIOMIN World Mycotoxin Survey Q1 2017,” 2018). However, DON was not found in our samples. In the study of Skládanka et al. (2014) were DON and T-2 toxin levels in grasses evaluated and they concluded that low temperature (especially below $5^{\circ} \mathrm{C}$ ) significantly inhibits mycotoxin production in forage. This can be caused by stress-mediated reduction of enzymatic activity of mycotoxigenic fungi. However, this would not be the case in our experiment, because the average temperatures were probably higher in the duration of experiment's growing season. The fact that DON was below the limit of quantification in our samples can be explained by other unsuitable conditions for its production or low detection limit of used ELISA kit. Detection limit in grain and feed is 200 ppb for used kit, therefore its content in wheat kernels were less than $200 \mathrm{ppb}$. Higher amounts of toxin from the same group (T-2) were detected $(24.34 \pm 8.25 \mathrm{ng} / \mathrm{ml})$. Optimal temperature for $\mathrm{T}-2$ toxin production is 11.9-15. $5^{\circ} \mathrm{C}$, which would corroborate our findings (Nazari et al., 2016; 2014). Interannual variability is an important factor in fungal pathogenesis and mycotoxin production, therefore further study of mycotoxin contamination is needed (Skládanka et al., 2014).

\section{CONCLUSION}

The main hypothesis was largely proven. SAP solution can serve as a suitable medium for delivering $\mathrm{Cu}$ particles as effectively as water. It was also proven, that $\mathrm{Cu}$ fertilization can affect nutritional status of wheat, mainly the fat, CF and cellulose content. There was no statistically significant difference in $\mathrm{Cu}$ treatments in case of the trichothecenes' contamination of wheat kernel.

\section{Acknowledgements}

The research was financially supported by the AF-1GA2020-TP007: Use of superabsorbent polymers with controlled nutrient release in field-crop cultivation systems in arid areas. 


\section{REFERENCES}

AZEEM, B., KUSHAARI, K., MAN, Z. B. et al. 2014. Review on materials \& methods to produce controlled release coated urea fertilizer. Journal of Controlled Release, 181: 11-21.

BIOMIN. 2018. BIOMIN World Mycotoxin Survey Q1 2017. Biomin. [Online]. Available at: http://www. biomin.net/nz/articles/biomin-world-mycotoxin-survey-q1-2017/ [Accessed 7 Aug 2018].

BRYDEN, W. L. 2011. Mycotoxins: Natural Food Chain Contaminants and Human Health. In: NRIAGU, J. O. (Ed.). Encyclopedia of Environmental Health. Burlington: Elsevier, pp. 898-905.

EUROPEAN COMMISION. 2009. Commission Regulation (EC) No 152/2009, on Laying down the Methods of Sampling and Analysis for the Official Control of Feed (Text with EEA Relevance). Brussels: EC. Available at: http://data.europa.eu/eli/reg/2009/152/oj/eng [Accessed 12 Dec 2020].

COLE, R. J., JARVIS, B. and SCHWEIKERT, M. A. 2003. Handbook of Secondary Fungal Metabolites. Vol. 1. Burlington: Academic Press.

CWALINA-AMBROZIAK, B., KUROWSKI, T. P., WAŚKIEWICZ, A. et al. 2017. The effect of fertiliser treatments on the severity of Fusarium head blight and mycotoxin biosynthesis in winter rye. Arhiv za Higijenu Rada i Toksikologiju, 68: 16-26.

DATNOFF, L. E., ELMER, W. H. and HUBER, D. M. 2007. Mineral Nutrition and Plant Disease. American Phytopathological Society. Deoxynivalenol in food and feed: occurrence and exposure, 2013. EFSA Journal, 11(10): 3379.

FERNÁNDEZ, V. and T. EICHERT. 2009. Uptake of Hydrophilic Solutes Through Plant Leaves: Current State of Knowledge and Perspectives of Foliar Fertilization. Critical Reviews in Plant Sciences 28(1-2): 36-68.

HAERR, K. J., LOPES, N. M., PEREIRA, N. M. et al. 2015. Corn silage from corn treated with foliar fungicide and performance of Holstein cows. Journal of Dairy Science, 98(12): 8962-8972.

HUANG, M.-R., HUANG, S.-J. and LI, X.-G. 2011. Facile Synthesis of Polysulfoaminoanthraquinone Nanosorbents for Rapid Removal and Ultrasensitive Fluorescent Detection of Heavy Metal Ions. Journal of Physical Chemistry C, 115(13): 5301-5315.

KELLER, A. A., ADELEYE, A. S., CONWAY, J. R. et al. 2017. Comparative environmental fate and toxicity of copper nanomaterials. NanoImpact, 7: 28-40.

KRISTL, J., SEM, V., KRISTL, M., KRAMBERGER, B. et al. 2019. Effects of integrated and organic pest management with copper and copper-free preparations on tomato (Lycopersicum esculentum Mill.) fruit yield, disease incidence and quality. Food Chemistry, 278: 342-349.

LOLAND, J. Ø. and SINGH, B. R. 2004. Copper contamination of soil and vegetation in coffee orchards after long-term use of $\mathrm{Cu}$ fungicides. Nutrient Cycling in Agroecosystems, 69: 203-211.

MALANDRAKIS, A. A., KAVROULAKIS, N. and CHRYSIKOPOULOS, C. V. 2019. Use of copper, silver and zinc nanoparticles against foliar and soil-borne plant pathogens. Science of The Total Environment, 670: 292-299.

MCMULLEN, M., JONES, R. and GALLENBERG, D. 1997. Scab of Wheat and Barley: A Re-emerging Disease of Devastating Impact. Plant Disease, 81(12): 1340-1348.

MIKULA, K., IZYDORCZYK, G., SKRZYPCZAK, D. et al. 2020. Controlled release micronutrient fertilizers for precision agriculture - A review. Science of the Total Environment, 712: 136365.

MORADI-GHAHDERIJANI, M., JAFARIAN, S. and KESHAVARZ, H. 2017. Alleviation of water stress effects and improved oil yield in sunflower by application of soil and foliar amendments. Rhizosphere, 4: 54-61.

RAMEZANI, M., RAMEZANI, F. and GERAMI, M. 2019. Nanoparticles in Pest Incidences and Plant Disease Control. In: PANPATTE, D. G. and JHALA, Y. K. (Eds.). Nanotechnology for Agriculture: Crop Production \& Protection. Sangapore: Springer, pp. 233-272.

RAMYADEVI, J., JEYASUBRAMANIAN, K., MARIKANI, A. et al. 2012. Synthesis and antimicrobial activity of copper nanoparticles. Materials Letters, 71: 114-116.

RODRIGUES, I. and NAEHRER, K. 2012. Prevalence of mycotoxins in feedstuffs and feed surveyed worldwide in 2009 and 2010. Phytopathologia Mediterranea, 51(1): 175-192.

SCHREIBER, L. and SCHÖNHERR, J. 2009. Water and Solute Permeability of Plant Cuticles: Measurement and Data Analysis. Berlin Heidelberg: Springer-Verlag.

SCHWARTZ, C., GÉRARD, E., PERRONNET, K. et al. 2001. Measurement of in situ phytoextraction of zinc by spontaneous metallophytes growing on a former smelter site. Science of the Total Environment, 279(1-2): 215-221.

SKLÁDANKA, J. 2014. Mycotoxins and molecular mass thiols in the grass forages. Brno: Mendel University in Brno, Department of Animal Nutrition and Forage Production.

THIPE, V. C., KEYSTER, M. and KATTI, K. V. 2018. Sustainable Nanotechnology: Mycotoxin Detection and Protection. In: ABD-ELSALAM, K. A. and PRASAD, R. (Eds.). Nanobiotechnology Applications in 
Plant Protection, Nanotechnology in the Life Sciences. Cham: Springer International Publishing, pp. 323-349.

TILLER, K. G. and MERRY, R. H. 1981. Copper pollution of agricultural soils. In: Copper in Soils and Plants: Golden Jubilee International Symposium on Copper in Soils and Plants. Sydney: Australian Academy of Technological Sciences.

VARA PRASAD, M. N. and DE OLIVEIRA FREITAS, H. M. 1999. Feasible biotechnological and bioremediation strategies for serpentine soils and mine spoils. Electronic Journal of Biotechnology, 2(1): 20-34.

WORRALL, E. A., HAMID, A., MODY, K. T. et al. 2018. Nanotechnology for Plant Disease Management. Agronomy, 8(12): 285.

YADAV, S. K. 2010. Heavy metals toxicity in plants: An overview on the role of glutathione and phytochelatins in heavy metal stress tolerance of plants. South African Journal of Botany, 76(2): 167-179.

ZADOKS, J. C., CHANG, T. T. and KONZAK, C. F. 1974. A Decimal Code for the Growth Stages of Cereals. Weed Research, 14(6): 415-421.

Contact information

Ivana Kolackova: ivana.kolackova@mendelu.cz

Hana Abigail Gruberova: xgrubero@mendelu.cz

Ondrej Kratochvil: kratochvil.o@email.cz

Daria Baholet: dariabaholet@gmail.com

Jiri Skladanka: jiri.skladanka@mendelu.cz

Josef Jancar: josef.jancar@ceitec.vutbr.cz

Petr Skarpa: petr.skarpa@mendelu.cz 